\title{
LETTERS
}

\section{Protein kinase signals activate interleukin 16 encoding transcripts in rheumatoid arthritis versus osteoarthritis synovial fibroblasts}

\author{
M K Schuler, S Sell, W K Aicher
}

Ann Rheum Dis 2003;62:182-183

nterleukin 16 (IL16) is a proinflammatory cytokine and a chemoattractant factor for CD4+ T cells. IL16 has been detected at higher concentrations in rheumatoid arthritis (RA) synovial fluid than in osteoarthritis(OA) specimens. IL16 is expressed in inflammatory infiltrates and in CD68 synovial lining cells of patients with RA as detected by in situ hybridisation. ${ }^{1-3}$

In this study we compared the modulation of ILl6 steady state mRNA in synovial fibroblasts (SF) from six patients with RA and from three patients with OA. SF were prepared, expanded, and characterised as described previously. ${ }^{4}$ To examine the IL16 encoding transcript amounts, SF were incubated in complete medium for 24 or 48 hours in the presence of one of the following chemicals: $1 \mathrm{ng} / \mathrm{ml}$ phorbol-12-myristate-13-acetate (PMA), an activator of protein kinase C (PKC); $200 \mathrm{ng} / \mathrm{ml}$ ionomycin (Iono), a calcium ionophor; $10 \mu \mathrm{M}$ of adenosine-3', $5^{\prime}$-cyclic monophosphate (cAMP), which stimulates protein kinase A (PKA); $10 \mathrm{nM}$ okadaic acid (Oka), a phosphatase inhibitor; $10 \mu \mathrm{M}$ MAS-7, which activates G-proteins; $100 \mu \mathrm{M} \mathrm{H}-7$ dihydrochloride (H-7), an inhibitor of protein kinases; and $10 \mathrm{nM}$ staurosporine (Stauro), a protein kinase inhibitor (all from Calbiochem or Biomol). Differences of IL16 encoding steady state mRNA amounts in activated cells compared with
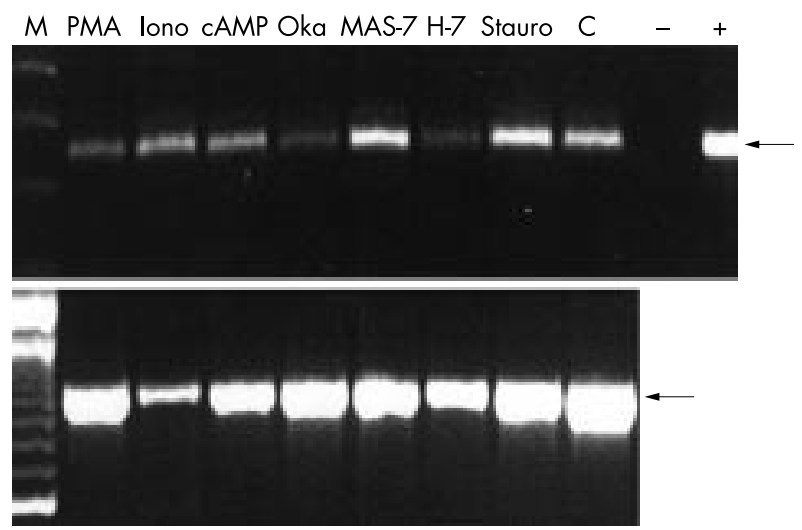

Figure 1 Modulation of IL16 transcripts in OA SF. SF of a patient with OA were expanded in culture and analysed for IL 16 transcripts during the second passage. The synovial fibroblasts were incubated with phorbol ester (PMA), ionomycin (lono), cAMP, okadaic acid (Oka), MAS-7, H-7, or staurosporine (Stauro). Untreated cells served as controls (C). OA SF transcribed IL 16 encoding mRNA (C). Staurosporine and MAS-7 enhanced the RT-PCR signal to some extent, whereas in PMA, Oka, and H-7 treated cells the ILI6 RT-PCR signal was reduced. A recombinant IL16 plasmid served as a positive control (+) and the RT-PCR master mix without cDNA served as a negative control (-, top). GAPDH RT-PCR served as control to show sufficient quality and quantity of the cDNA employed (bottom). A 100 bp DNA marker shows PCR product sizes (M). controls were detected after 33 cycles of reverse transcriptasepolymerase chain reaction (RT-PCR) amplification (Taq DNA polymerase, Roche Biochemicals). ${ }^{1}$ Glyceraldehyde-3phosphate dehydrogenase (GAPDH) RT-PCR served as a control for RNA content. The PCR amplification plateau was reached after 35 cycles. This suggested that the IL16-specific RT-PCR was suitable for detecting different levels of IL16 encoding transcripts as the PCR was stopped before reaching the amplification plateau. Still, the limitations of this method are evident and we therefore consider our data as a semiquantitative enumeration of transcripts encoding ILl6.

Both, early passage RA SF and OA SF spontaneously transcribed IL16 encoding mRNA. Addition of protein kinase inhibitor staurosporine enhanced the IL16 RT-PCR signals in all samples of OA SF, whereas specific protein kinase C activator PMA reduced the IL16 encoding RT-PCR signals in OA SF ( fig 1). Ionomycin, CAMP, and MAS-7 had minor and variable effects in OA SF (fig 1). Addition of protein kinase inhibitor staurosporine also enhanced the IL16 encoding signal in RA SF (fig 2). Incubation of the cells with PMA and ionomycin reduced the IL16 encoding RT-PCR signal intensity in these cells (fig 2). Again, cAMP and MAS-7 produced minor and variable effects in the different samples analysed (fig 2). Application of okadaic

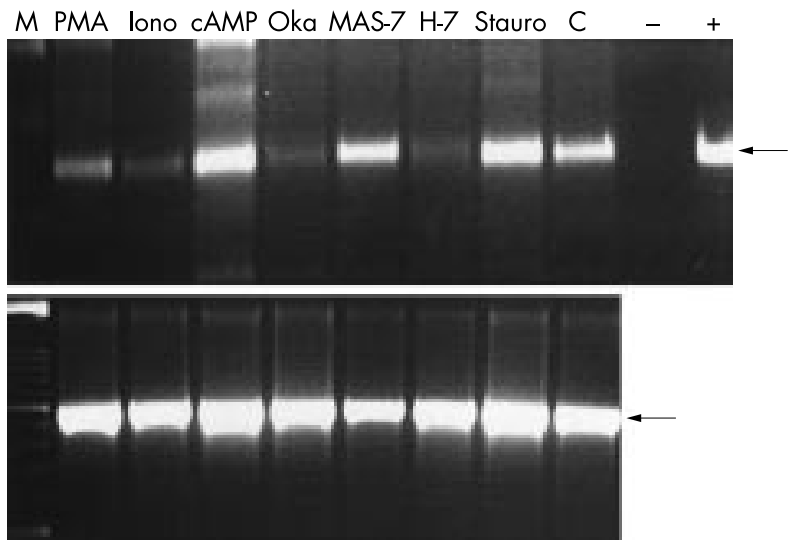

Figure 2 Regulation of IL 16 transcripts in RA SF. SF of a patient with RA were expanded and analysed for IL 16 transcripts in the second passage. The synovial fibroblasts were incubated with phorbol ester (PMA), ionomycin (lono), cAMP, okadaic acid (Oka), MAS-7, H-7, or staurosporine (Stauro). Untreated cells served as controls (C). RA synovial fibroblasts spontaneously transcribed IL 16 encoding mRNA (C). cAMP and staurosporine enhanced the RT-PCR signal. In PMA, lono, Oka, and H-7 treated cells the IL16 RT-PCR signal was reduced. A recombinant IL16 plasmid served as a positive control (+) and the RT-PCR master mix without cDNA as a negative control (-, top). GAPDH RT-PCR served as a control to show sufficient quality and quantity of the cDNA employed (bottom). A 100 bp DNA marker shows PCR product sizes (M). 
acid or H-7 dihydrochloride reduced the IL16 RT-PCR signals. As okadaic acid and H-7 reduced the cell viability prominently, the decreased IL16 signals probably result from the induction of cell death. In contrast, incubation of the cells with PMA, ionomycin, cAMP, MAS-7, or staurosporine did not reduce the viability.

Protein kinase inhibitor staurosporine has been reported to induce apoptosis in some cells. ${ }^{5}$ Enumeration of dead cells and observation of morphological changes by microscopy upon staurosporine treatment did not give any indication of reduced cell viability at concentrations 10- to 100-fold above the concentrations used in our experiments. RA SF are resistant to induction apoptosis by overexpression of sentrin, Bcl-2, and mutant forms of p53..$^{-9}$ Therefore the RA SF, especially, may be able to respond to a staurosporine induced pathway with enhanced IL16 transcript amounts. Because protein kinase C activator PMA reduced IL16 transcripts in SF, the data suggest that in SF the transcription of ILl6 might be regulated through protein kinase C dependent pathways.

\section{ACKNOWLEDGEMENTS}

We thank A Hack for excellent technical service. This study was supported by grants to WKA (fortüne 411 , in part by DFG Ai 16/10-1) and by institutional funding.

\section{Authors' affiliations}

M K Schuler, S Sell, W K Aicher, Centre for Orthopaedic Surgery, UKT

University Hospital, Tübingen, Germany
Correspondence to: Dr W K Aicher, Research Laboratory, University Medical Centre for Orthopaedic Surgery, Pulvermuehlstrasse 5, D 72070 Tübingen, Germany; Aicher@uni-tuebingen.de

Accepted 20 June 2002

\section{REFERENCES}

1 Franz JK, Kolb SA, Hummel KM, Lahrz F, Neidhart M, Aicher WK, et al. Interleukin-16, produced by synovial fibroblasts, mediates chemoattraction for $C D 4^{+}$T lymphocytes in rheumatoid arthritis. Eur J Immunol 1998;28:2661-71.

2 Klimiuk PA, Goronzy JJ, Weyand CM. IL-16 as an anti-inflammatory cytokine in rheumatoid synovitis. J Immunol 1999; 162:4293-9.

3 Blaschke S, Schulz H, Schwarz G, Blaschke V, Müller GA, Reuss-Borst M. Interleukin 16 expression in relation to disease activity in rheumatoid arthritis. J Rheumatol 2001;28:12-21.

4 Aicher WK, Heer AH, Trabandt A, Bridges SL Jr, Schroeder HW Jr, Stransky $G$, et al. Overexpression of zinc-finger transcription factor Z-225/Egr-1 in synoviocytes from rheumatoid arthritis patients. J Immunol 1994; 152:5940-8

5 Krick S, Platoshyn O, McDaniel SS, Rubin L, Yuan JX. Augmented K(+) currents and mitochondrial membrane depolarization in pulmonary artery myocyte apoptosis. Am J Physiol Lung Cell Mol Physiol 2001;281:887-94.

6 Firestein GS, Echeverri F, Yeo M, Zvaifler NJ, Green DR. Somatic mutations in the p53 tumor suppressor gene in rheumatoid arthritis synovium. Proc Natl Acad Sci USA 1997;94:10895-900.

7 Matsumoto S, Müller-Ladner U, Gay RE, Nishioka K, Gay S. Ultrastructural demonstration of apoptosis, Fas and Bcl-2 expression of rheumatoid synovial fibroblasts. J Rheumatol 1996;23:1345-52.

8 Aicher WK, Peter HH, Eibel H. Human synovial fibroblasts are resistant to anti-CD95 (fas) induced apoptosis [abstract]. Arthritis Rheum 1996;39:S75.

9 Franz JK, Pap T, Hummel KM, Nawrath M, Aicher WK, Shigeyama Y, et al. Expression of sentrin, a novel antiapoptotic molecule, at sites of synovial invasion in rheumatoid arthritis. Arthritis Rheum 2000;43:599-607.

\section{Obstructive sleep apnoea as a cause of fatigue in ankylosing spondylitis}

\section{N Erb, D Karokis, J P Delamere, M J Cushley, G D Kitas}

$\mathrm{F}$ atigue is a common symptom in ankylosing spondylitis (AS) occurring in $65 \%$ of patients ${ }^{12}$ and forms part of the Bath Ankylosing Spondylitis Disease Activity Index (BASDAI). ${ }^{3}$ Fatigue has been attributed to sleep disturbance from back pain and stiffness and usually increases with increased disease activity, but can occur independently of AS activity, suggesting the possibility of other causes. ${ }^{12}$ One such cause in the middle aged population is sleep apnoea syndrome (SAS). SAS is defined as 10 or more episodes an hour of airflow interruption for $\geqslant 10$ seconds during sleep. It occurs in up to $4 \%$ of middle aged people, ${ }^{5}$ and is associated with increased morbidity and mortality due to higher rates of cardiovascular disease and increased accidents. ${ }^{67}$

We suggest that AS predispose subjects to SAS through several mechanisms, including: restriction of the oropharyngeal airway from temporomandibular joint involvement or cervical spine disease causing pharyngeal and tracheal compression (as has been described in rheumatoid arthritis $^{8}$ ); cervical spine disease causing compression of the respiratory centres in the medulla resulting in central depression of respiration; or restrictive pulmonary disease. We carried out an observational study to assess the prevalence of SAS, and to investigate whether it contributes to fatigue in AS.

\section{PATIENTS AND METHODS}

Consenting volunteers with classical AS (modified New York Criteria 1984) were recruited prospectively from a hospital rheumatology clinic and assessed using: $(a)$ the BASDAI ${ }^{3} ;(b)$ the Epworth Sleepiness Scale (ESS), ${ }^{9}$ a validated self administered eight item questionnaire that assesses daytime sleepiness in adults (a score of $\leqslant 10$ is normal); (c) the Hospital Anxiety and Depression Scale (HAD) ${ }^{10}$ (a score of $\leqslant 7$ indicates normal mood); (d) height, weight, neck circumference; (e) spinal mobility by occiput-wall distance, chest expansion, and Schöber's test; $(f)$ respiratory measurements consisting of full spirometry and carbon monoxide diffusion studies, arterial blood gases, and night oximetry on two consecutive nights (using a five channel EdenTec Recorder and EdenTrace Software Version 1.3, Nellcor, Puritan and Bennett, Ltd) to assess heart rate, chest impedance, nasal airflow, oxygen saturation, and snoring level.

\section{RESULTS}

Of 22 recruited patients, 17 (77\%) completed the assessments, 14 male and three female. Pulmonary function testing was normal in nine $(53 \%)$ patients, classically restrictive in six $(35 \%)$, borderline restrictive in two $(12 \%)$, and obstructive in none. Two $(12 \%)$ patients fulfilled criteria for SAS when 


\begin{tabular}{|c|c|c|c|c|c|c|}
\hline Variable & $\begin{array}{l}\text { Total group } \\
\mathrm{n}=17 \text { (SD) }\end{array}$ & $\begin{array}{l}\text { No SAS } \\
\mathrm{n}=15 \text { (SD) }\end{array}$ & $t$ Test $(\mathrm{p})$ & $\mathrm{SAS} n=2(\mathrm{SD})$ & Patient 1 & Patient 2 \\
\hline Age (years) & $47.1(12.8)$ & $\begin{array}{l}46.9 \\
(13.5)\end{array}$ & 0.76 & $49.0(7.1)$ & 54 & 44 \\
\hline Disease duration (years) & $26.2(13.3)$ & $\begin{array}{l}26.1 \\
(14.2)\end{array}$ & 0.86 & $27.0(4.2)$ & 30 & 24 \\
\hline BASDAI & $4.9(1.8)$ & $4.8(1.9)$ & 0.59 & $5.5(1.3)$ & 4.6 & 6.4 \\
\hline Fatigue component of BASDAI & $6.0(2.5)$ & $5.8(2.5)$ & 0.04 & $8.0(0.7)$ & 8.5 & 7.5 \\
\hline HAD & $5.3(3.0)$ & $4.9(2.9)$ & 0.35 & $8.0(2.8)$ & 6 & 10 \\
\hline ESS & $9.7(5.5)$ & $8.6(5.1)$ & $<0.01$ & $16.5(0.7)$ & 17 & 22 \\
\hline Alcohol (units/week) & $6.7(8.9)$ & $7.5(9.1)$ & 0.01 & $0.0(0.0)$ & 0 & 0 \\
\hline Smoking (cigarettes/day) & $6.7(8.7)$ & $6.2(8.4)$ & 0.77 & $10.0(14.1)$ & 0 & 20 \\
\hline Body mass index & $26.4(5.0)$ & $25.6(4.6)$ & 0.13 & $32.7(3.1)$ & 30.5 & 34.9 \\
\hline Neck circumference $(\mathrm{cm})$ & $39.4(8.7)$ & $39.2(9.2)$ & 0.02 & $41.0(4.2)$ & 38 & 44 \\
\hline Occiput wall $(\mathrm{cm})$ & $5.9(5.0)$ & $5.5(4.4)$ & 0.71 & $9.0(9.9)$ & 2 & 16 \\
\hline Schobers $(\mathrm{cm})$ & $4.8(4.0)$ & $5.1(4.2)$ & 0.23 & $3.0(1.4)$ & 4 & 2 \\
\hline Chest expansion $(\mathrm{cm})$ & $2.9(1.8)$ & $3.1(1.8)$ & 0.09 & $1.5(0.7)$ & 2 & 1 \\
\hline
\end{tabular}

SAS, sleep apnoea syndrome; BASDAI, Bath Ankylosing Spondylitis Disease Activity Index; HAD, Hospital Anxiety and Depression Scale; ESS, Epworth Sleepiness Scale.

assessed by night oximetry. Both these patients had an obstructive type of SAS (table 1 ). ${ }^{3}$

Compared with those without SAS, the two patients with SAS had significantly higher mean ESS scores (SAS 16.5 (0.7) $v$ no SAS $8.6(5.1), \mathrm{p}<0.01)$, fatigue component of the BASDAI (SAS $8.0(0.7) v$ no SAS $5.8(2.5), \mathrm{p}=0.04)$, and neck circumference (SAS $41.0(4.2) v$ no SAS 39.2 (9.2), $\mathrm{p}=0.02$ ). The overall BASDAI scores (SAS 5.5 (1.3) $v$ no SAS 4.83 (1.9), $\mathrm{p}=0.59$ ) and body mass index (SAS 32.7 (3.1) $v$ no SAS 25.6 (4.6), $\mathrm{p}=0.13$ ) were not significantly different between the two groups. Neither of the two patients with SAS drank alcohol, but no other significant differences were found between the two groups (table 1).

\section{DISCUSSION}

SAS and AS can coexist. We found a higher prevalence of SAS in patients with AS (12\%) than has been reported in the general population (1-4\%). ${ }^{11}$ However the sample size was small and a larger study would be required to determine the true prevalence. As might be expected, the patients with SAS had high subjective scores of daytime sleepiness, which was mirrored by the high scores on the fatigue component of the BASDAI. The overall BASDAI scores of the patients with SAS were not significantly different from the remainder of the cohort, suggesting that disease activity in these two patients did not differ from that of the cohort, and the high fatigue component scores were rogue results reflecting the underlying SAS and not AS activity. None of the specific measurements of spinal involvement in the affected patients were significantly different from those of the cohort, suggesting that the degree of spinal involvement in AS was not a contributing factor in the development of SAS in these two subjects. The two affected patients were both obese middle aged men and had a classical restrictive pattern on pulmonary function testing, all of which are known to be risk factors for the development of SAS. Both patients were treated with continuous positive airway pressure ventilation at night, and their levels of fatigue improved subjectively, which was reflected in a fall of their ESS scores (patient 1: 17 to 9, patient 2: 22 to 12).

SAS can be a contributing factor to fatigue in AS. Patients with excessive fatigue or scoring high on the fatigue component of the BASDAI without other evidence for continuing disease activity should be assessed for other causes of fatigue. Detection and treatment of SAS can lead to improvement in fatigue symptoms in these patients and reduce the associated morbidity and mortality of SAS.

\section{ACKNOWLEDGEMENTS}

Many thanks to the staff of the Pulmonary Function Laboratories in the Dudley Group of Hospitals NHS Trust for carrying out the respiratory tests and sleep studies.

\section{Authors' affiliations}

N Erb, D Karokis, J P Delamere, G D Kitas, Department of Rheumatology, Dudley Group of Hospitals NHS Trust, UK

M J Cushley, Department of Respiratory Medicine, Dudley Group of Hospitals NHS Trust, UK

Correspondence to: Dr N Erb, Department of Rheumatology, Dudley Group of Hospitals NHS Trust, The Guest Hospital, Tipton Road, Dudley West Midlands DY1 4SE, UK; niki@erb.org.uk

Accepted 7 June 2002

\section{REFERENCES}

1 Jones SD, Koh WH, Steiner A, Garrett SL, Calin A. Fatigue in ankylosing spondylitis: its prevalence and relationship to disease activity, sleep, and other factors. J Rheumatol 1996;23:487-90.

2 Calin A, Edmunds L, Kennedy LG. Fatigue in ankylosing spondylitis - why is it ignored? J Rheumatol 1993;20:991-5.

3 Garrett S, Jenkinson T, Kennedy LG, Whitelock H, Gaisford P, Calin A. A new approach to defining disease status in ankylosing spondylitis: the Bath Ankylosing Spondylitis Disease Activity Index. J Rheumatol 1994;21:2286-91

4 Calin A, Nakache JP, Gueguen A, Zeidler H, Mielants H, Dougados M. Defining disease activity in ankylosing spondylitis: is a combination of variables (Bath Ankylosing Spondylitis Disease Activity Index) an appropriate instrument? Rheumatology (Oxford) 1999;38:878-82.

5 Skomro RP, Kryger MH. Clinical presentations of obstructive sleep apnea syndrome. Prog Cardiovasc Dis 1999:41:331-40.

6 Newman AB, Spiekerman CF, Enright $P$, Lefkowitz D, Manolio T, Reynolds CF, et al. Daytime sleepiness predicts mortality and cardiovascular disease in older adults. The Cardiovascular Health Study Research Group. J Am Geriatr Soc 2000;48:1 15-23.

7 Peker Y, Kraiczi H, Hedner J, Loth S, Johansson A, Bende M. An independent association between obstructive sleep apnoea and coronary artery disease. Eur Respir J 1999;14:179-84.

8 Pepin JL, Della Negra E, Grosclaude S, Billon C, Levy P. Sleep apnoea syndrome secondary to rheumatoid arthritis. Thorax 1995;50:692-4; discussion 696-7.

9 Johns MW. A new method for measuring daytime sleepiness: the Epworth sleepiness scale. Sleep 1991;14:540-5.

10 Herrmann C. International experiences with the Hospital Anxiety and Depression Scale-a review of validation data and clinical results. J Psychosom Res 1997;42:17-41.

11 Odens ML, Fox CH, Adult sleep apnea syndromes. Am Fam Physician 1995;52:859-66, 871-2. 


\title{
Thoracic high resolution computed tomography in patients with ankylosing spondylitis and without respiratory symptoms
}

\author{
A El Maghraoui, S Chaouir, A Bezza, F Tabache, A Abouzahir, D Ghafir, V Ohayon, \\ M I Archane
}

T: he incidence of pleuropulmonary disease in ankylosing spondylitis (AS) varies from 0 to $30 \%$ in the medical literature. ${ }^{1-4}$ The most frequently recognised manifestations are upper lobe fibrosis, mycetoma formation, and pleural thickening. The advent of high resolution computed tomography (HRCT) made it possible to examine the entire lung parenchyma and pleura in many conditions with diffuse lung disease by a non-invasive method.

Consecutive patients with a diagnosis of AS according to the modified New York criteria ${ }^{5}$ who attend our department during one year were included in the study. All patients had a prospective rheumatological assessment conducted by two rheumatologists (AEM and $\mathrm{AB}$ ) using a structured questionnaire, a pulmonary function testing measurement, posteroanterior chest radiography; on the same day an HRCT of the thorax was performed using a Siemens Somatom S CT scanner with images windowed to highlight both lung and mediastinal structures. Nine HRCT slices were obtained on suspended respiration at 2 $\mathrm{cm}$ intervals from the lung apices to bases. The results of the chest radiographs and HRCT were assessed by a radiologist (SC) who was unaware of the clinical data of the patient. The CT scans were evaluated for the presence, distribution, and extent of airway and parenchymal abnormalities. Standard CT criteria were used to establish a diagnosis of interstitial lung disease (ILD), bronchiectasis, and emphysema.

Plain radiography was abnormal in only two patients. Twenty four patients $(55 \%)$ showed abnormalities on HRCT. Table 1 lists the abnormalities detected on HRCT. Twenty (45\%) patients had mild non-specific interstitial abnormalities of insufficient severity or extent to be labelled as ILD. Pulmonary function tests showed a restrictive process in eight patients, in whom three had normal chest HRCT and three had ILD. The two remaining patients had non-specific interstitial abnormalities (blebs, pleural thickening, parenchymal bands). Two patients had an obstructive process: one had normal chest HCRT and the other emphysema and apical fibrosis.

\begin{tabular}{|lc|}
\hline \multicolumn{2}{|l|}{$\begin{array}{l}\text { Table } 1 \quad \text { Results of chest HRCT in } 44 \\
\text { patients with anklosing spondylitis }\end{array}$} \\
\hline & Number (\%) \\
\hline Normal & $20(45)$ \\
Emphysema & $5(11)$ \\
Interstitial lung disease & $4(9)$ \\
Upper lobe fibrosis & $3(7)$ \\
Bronchiectasis & $2(5)$ \\
Ground glass attenuation & $1(2)$ \\
Non-specific interstitial change & $20(45)$ \\
Pleural thickening & $12(27)$ \\
Parenchymal bands & $10(23)$ \\
Subpleural bands & $6(14)$ \\
Blebs & $6(14)$ \\
Parenchymal micronodules & $4(9)$ \\
Irregular interfaces & $3(7)$ \\
\hline \multicolumn{2}{l}{} \\
\hline
\end{tabular}

Our study disclosed a great percentage of defined as well as mild and non-specific interstitial abnormalities on HRCT undetectable on plain radiography in a series of patients with AS and without history of respiratory symptoms. Only one patient had evidence of ground glass shadowing, which is associated with active alveolitis (fig 1). This is usually considered a feature of early and potentially reversible disease. As previously described, the overall correlation of pulmonary function with radiographic appearance was poor. Casserly and Fenlon studied 26 patients with AS using HRCT and noted pulmonary abnormalities in 19 patients $(73 \%) .{ }^{67}$ Findings consisted of interstitial lung disease (four patients), bronchiectasis (six patients), emphysema (four patients), apical fibrosis (two patients), mycetoma (one patient), and non-specific interstitial lung disease ( 12 patients). In that study plain radiographs revealed abnormalities in four patients. In contrast with our study, all patients with ILD had respiratory symptoms.

Another study conducted by Turetschek et al showed that 15/21 (71\%) patients had abnormalities on thin section CT. ${ }^{8}$ The most common abnormalities were thickening of the interlobular septa (7/21 patients), mild bronchial wall thickening (6/21), pleural thickening and pleuropulmonary irregularities (6/21), and linear septal thickening $(6 / 21)$. The HRCT findings in our study, as was the case in the study of Casserly et al, ${ }^{6}$ suggest an inflammatory process rather than a mechanical cause for the interstitial disease found in patients with AS. Twenty patients $(45 \%)$ in our study had non-specific interstitial abnormalities as had $11(42 \%)$ patients in the study of Casserly et al, which implied HRCT evidence of interstitial change that was of insufficient severity or extent to be labelled as ILD. The significance of such changes is unknown and must await a prospective longitudinal study to determine their natural history.

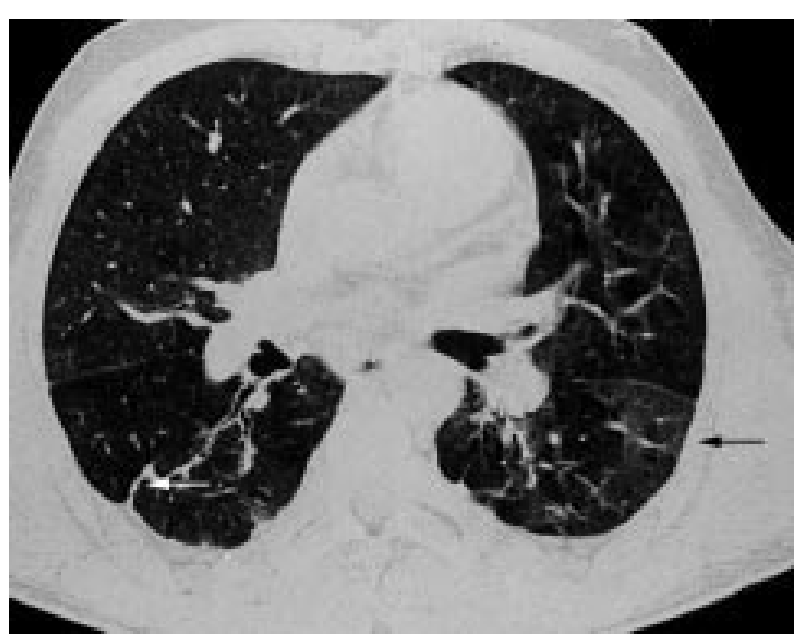

Chest HRCT of a 37 year old patient showing ground glass aspect (black arrow) with parenchymal band (white arrow). 


\section{ACKNOWLEDGEMENT}

Supported in part by a grant from Pfizer.

\section{Authors' affiliations}

A El Maghraoui, A Bezza, F Tabache, A Abouzahir, D Ghafir, V Ohayon, M I Archane, Internal Medicine Department, Military Hospital Mohamed V, Rabat, Morocco

S Chaouir, Radiology Department, Military Hospital Mohamed V, Rabat, Morocco

Correspondence to: Professor A El Maghraoui;

a_elmaghraovi@hotmail.com

Accepted 14 May 2002

REFERENCES

1 Davies D. Ankylosing spondylitis and lung fibrosis. Q J Med 1972;41:395-417.
2 Appelrouth D, Gottlieb NL. Pulmonary manifestations of ankylosing spondylitis. J Rheumatol $1975 ; 2: 446-53$

3 Feltelius N, Hedenstrom H, Hillerdal G, Hallgren R. Pulmonary involvement in ankylosing spondylitis. Ann Rheum Dis 1986:45:736-40.

4 Bouchea DK, Sundstrom WR. The pleuropulmonary manifestations of ankylosing spondylitis. Semin Arthritis Rheum 1989;18:277-81.

5 Van der Linden S, Valkenburg HA, Cats A, Evaluation of diagnostic criteria for ankylosing spondylitis. A proposal for modification of the New York criteria. Arthritis Rheum 1984;27:361-8.

6 Casserly IP, Fenlon HM, Breanatch E, Sant FM. Lung findings on high-resolution computed tomography in idiopathic ankylosing spondylitis. Correlation with clinical findings, pulmonary function tresting and plain radiography. Br J Rheumatol 1997;36:677-82.

7 Fenlon HM, Casserly I, Sant SM, Breanatch E. Plain radiographs and thoracic high-resolution computed tomography in patients with ankylosing spondylitis. AJR Am J Roentgenol 1997;168:1067-72.

8 Turetschek K, Ebner W, Fleischmann D, Wunderbaldinger $\mathrm{P}$ Erlacher L, Zontsich T, et al. Early pulmonary involvement in ankylosing spondylitis: assessment with thin-section CT. Clin Radiol 2000;55:632-6.

\title{
Effect of low dose weekly methotrexate on bone mineral density and bone turnover
}

\author{
S Patel, G Patel, D Johnson, L Ogunremi, J Barron
}

W ijnands and Burgers recently reported on a patient with psoriasis who developed stress fracture of the leg thought to be related to methotrexate treatment. ${ }^{1}$ The role of methotrexate in the aetiology of fractures remains uncertain, because nearly all subjects reported had other risk factors for fracture, such as the underlying disease being treated. We recently examined a group of patients with psoriasis (without features of arthritis, to avoid the bias which may occur due to the arthritis and compensatory action of methotrexate on inflammatory disease activity $)^{2}$ to assess the effect of methotrexate on bone density and turnover.

After approval from the local ethics committee, patients with psoriasis, but without psoriatic arthritis or diseases or drug treatment known to adversely effect the skeleton, were recruited. We obtained information by interview and measured bone mineral density (BMD) by dual $x$ ray absorptiometry (DXA) using a Lunar DPX device (Lunar Corp, Madison, WI). Daily calibration measurements using an external phantom were performed and monitored for machine drift. No significant drift was noted during the study period. Precision was calculated by the method of Gluer et $\mathrm{al}^{2}{ }^{2}$ and at our centre is $1.3 \%$ for the lumbar spine and $1.8 \%$ for the femoral neck. Morning samples of blood and second void urine were taken for biochemical analysis. Data are presented as mean (SD) unless stated. The significance of differences between groups was tested using paired and unpaired Student's $t$ tests where appropriate. One sample $t$ test was used to determine if age adjusted BMD ( $Z$ scores) were significantly different from the densitometer control database. Correlations were examined using linear regression. A value of $\mathrm{p}<0.05$ was considered significant.

Baseline assessments were performed on 30 patients, and 20 subsequently agreed to have repeat bone densitometry a mean of 21 months (range 17-24) later. The patients comprised 12 men and 18 women with a mean age of 56 years (range 32-85). Of the 18 women, 10 were postmenopausal (mean duration 21 years, range 3-39). All patients had been treated with methotrexate for a median duration of 2.0 years (interquartile range (IQR) 1.4-5.6). The cumulative median dose was $1387 \mathrm{mg}$ (IQR 654-2250) and the weekly median dose was $9.8 \mathrm{mg}$ (IQR 6.8-15.1).

Bone density was normal at the lumbar spine and femoral neck at baseline. Lumbar spine BMD was $1.205(0.215) \mathrm{g} / \mathrm{cm}^{2}$, the $\mathrm{T}$ score was -0.09 (1.98), and the $\mathrm{Z}$ score 0.833 (1.703). Respective values for the femoral neck were 0.938 (0.174) $\mathrm{g} / \mathrm{cm}^{2},-0.654$ (1.463), and 0.224 (1.109). BMD did not change significantly from baseline in the 20 patients who participated in the longitudinal phase of this study. There was no relationship between weekly or cumulative methotrexate dose and change in BMD over this period of time. Baseline biochemistry of the patients was normal including parathyroid hormone and markers of bone turnover. There was no significant correlation between the duration of methotrexate use or dose (weekly and cumulative), BMD or markers of bone turnover. There were no differences in BMD Z scores for either skeletal sites or bone markers when women were classified according to menopausal status. Similarly the sex of the subject did not affect BMD Z scores or bone markers.

We report the effects of methotrexate on BMD and bone turnover at baseline and over two years in patients treated with methotrexate for psoriasis. We found that the prevalence of osteoporosis was no greater than would be expected for the age of the patient ( $\mathrm{Z}$ scores were normal) and that for most patients, markers of bone turnover at baseline were within the normal range. Also no change in BMD was found when a subgroup of 20 patients were followed up prospectively. Bone turnover was normal and there was no change in BMD with chronic treatment. The rationale for choosing the patients studied was to avoid any confounding effects of underlying disease such as rheumatoid arthritis, which can itself cause local and systemic osteoporosis and abnormal bone turnover. ${ }^{2}{ }^{4}$ None of our patients had systemic inflammatory disease and a recent study confirms that chronic psoriasis is not associated with osteoporosis. ${ }^{5}$

In our study BMD was measured at the standard skeletal sites for the diagnosis of osteoporosis. We did not measure BMD at sites of stress fracture reported with methotrexate, 
which typically are the metatarsals or distal tibia as reported by Wijnands and Burgers. ${ }^{1}$ These skeletal sites have a high cortical bone content and are under different and potentially greater mechanical strain than the spine or hip site. Thus whether methotrexate causes regional bone loss and whether mechanical strain is important in the pathogenesis of these stress fractures remains uncertain. Other limitations of our study include the relatively small sample size and short duration of follow up (21 months) which may result in type 2 errors. We also had to rely on the Lunar DPX manufacturer's control database to act as a control group as we did not have an aged match control group at baseline. Other confounding factors are that as the longitudinal phase was some time after initiation of methotrexate, early bone loss might have been missed, although this seems unlikely, as baseline Z scores were normal. We were only able to recruit 20 of the original 30 patients who participated in the cross sectional phase of this study, but this was owing to patient preference rather than side effects or lack of efficacy of the treatment. All the patients received methotrexate continuously during follow up. Although the dose of methotrexate in the patients studied was relatively low (median weekly dose $9.8 \mathrm{mg}$ ), we did not find a relationship between weekly or cumulative dose and bone turnover or BMD (both baseline and longitudinally).

In summary, our findings suggest that weekly methotrexate treatment in the doses used in this study, is unlikely to increase fracture risk at the common skeletal sites for osteoporotic fractures.

....................

Authors' affiliations

S Patel, G Patel, D Johnson, Department of Rheumatology, St Helier Hospital, Epsom and St Helier NHS Trust, UK

J Barron, Department of Chemical Pathology, St Helier Hospital

S Patel, L Ogunremi, Osteoporosis Unit, Department of Rheumatology, St George's Hospital, UK

Correspondence to: Dr S Patel, Department of Rheumatology, St Helier Hospital, Carshalton, Surrey SM5 1AA, UK; spatel@sthelier.sghms.ac.uk

Accepted 10 June 2002

\section{REFERENCES}

1 Wijnands $M$, Burgers $A$. Stress fracture in long term methotrexate treatment for psoriaritic arthritis. Ann Rheum Dis 2001;60:736-8. 2 Mazzantini M, Di Munno O. Methotrexate and bone mass. Clin Exp Rheumatol 2000; 18:S87-92.

3 Gluer CC, Blake G, Blunt BA, Jergas M, Genant K. Accurate assessment of precision errors: how to measure the reproducibility of bone densitometry techniques. Osteoporos Int 1995:5:262-70.

4 Lems WF, Dijkmans BAC. Should we look for osteoporosis in patients with rheumatoid arthritis?Ann Rheum Dis 1998;57:325-7.

5 Millard TP, Antoniades L, Evans AV, Smith HR, Spector TD, Barker JN. Bone mineral density of patients with chronic plaque psoriasis. Clin Exp Dermatol 2001;26:446-8.

\title{
Evaluation of a screening tool for inflammatory joint disease
}

\author{
J A Barbour, J Binding, M Bridges, C Kelly
}

Ann Rheum Dis 2003;62:187-188

$\mathrm{T}$ he benefit of early treatment of inflammatory joint disease (IJD) with disease modifying drugs (DMARDs) to avoid progressive irreversible joint damage is well established. The time delay from onset of symptoms to starting a DMARD is determined by a number of factors, and early synovitis clinics have been developed to facilitate speedy referral and initiation of DMARD treatment. The efficiency of these clinics is dependent on appropriate referral. ${ }^{1}$ Diagnosing early IJD is not easy; even specialists have been shown to disagree when tested. ${ }^{2}$ Therefore an effective screening tool could be used to maximise identification of patients likely to have IJD and minimise unnecessary use of urgent appointments.

A simple eight point questionnaire (box 1) was devised to separate patients with and without IJD. It uses well recognised diagnostic criteria for rheumatoid arthritis (morning stiffness, rheumatoid factor, and erosions) but also includes more general markers of inflammation (erythrocyte sedimentation rate (ESR)), benefit from non-steroidal anti-inflammatory drugs (NSAIDs)/steroids, synovitis, and family history.

We prospectively studied 100 consecutive patients whom their general practitioner (GP) suspected might have IJD and had referred to one consultant for early assessment over a 10 month period. GP letters were initially screened by the consultant and then passed to the nurse practitioner who applied the questionnaire (box 1) to all patients before the consultant's assessment.

Characteristic distribution for IJD was positive if more than one joint was affected by pain or stiffness, but negative if the pattern affected predominately the distal interphalangeal joints of the hands or the base of the thumbs. Synovitis was defined as the affected joint being tender and swollen. The most recent ESR was used, radiographs of hands and feet were used for assessment of erosions, and benefit from NSAID/ steroids was taken as a reported patient global assessment. The diagnosis was taken as that made by the consultant at the first assessment. In cases where there was some doubt, it was taken as the most likely diagnosis at the subsequent review appointment. Seventy six women and 24 men not known to have IJD were included with mean ages of 55 years (women) and 50 years (men). The consultant diagnosed 31 as having IJD, of whom 30 scored 3 or more on the questionnaire (27 rheumatoid arthritis, 2 psoriatic arthritis, 1 palindromic

\section{Box 1 Questionnaire.}

The presence or absence of the following items was recorded.

- Early morning stiffness $>1$ hour

- Characteristic distribution for IJD

- First degree relative with IJD

- Clinical evidence of synovitis

- $E S R \geqslant 20 \mathrm{~mm} / 1 \mathrm{st} \mathrm{h}$ (men), $\geqslant 30 \mathrm{~mm} / 1 \mathrm{st} \mathrm{h}$ (women)

- Positive rheumatoid factor $(\geqslant 1 / 80)$

- Erosions on hands or feet $x$ ray

- Benefit from NSAID or steroids 
arthritis). Sixty nine patients were diagnosed as having nonIJD, of whom 31 scored 3 or more on the questionnaire and 38 scored less than 3 . For a score of 3 or more the questionnaire diagnosed IJD with a sensitivity of $97 \%(30 / 31)$, a specificity of $55 \%(38 / 69)$, a positive predictive value of $49 \%(30 / 61)$ and a negative predictive value of $97 \%$ (38/39).

Given both its accuracy in identifying patients with non-IJD and high sensitivity in identifying patients with IJD, the questionnaire appears to offer a means of differentiating urgent referrals from routine cases. Further studies are necessary to establish reproducibility of the tool when used by other medical and nursing staff, in the hope that GPs could use this tool to determine the urgency of referral-using three or more positive answers as criteria for prompt action. This will potentially reduce delay from onset of symptoms to initiation of DMARD treatment in patients with IJD.

\section{Authors' affiliations}

J A Barbour, J Binding, M Bridges, C Kelly, Department of Rheumatology, Queen Elizabeth Hospital, Sheriff Hill, Gateshead NE9 6SX, UK

Correspondence to: Dr C Kelly; kelly6.family@breathemail.net

Accepted 20 June 2002

\section{REFERENCES}

1 Gough A, Young A, Bacon P. Objectives and outcome of running an early inflammatory arthritis clinic. Baillieres Clin Rheumatol 1992;6:261-83

2 Gormley G, Steele K, Gilliland D, Stevenson M, O'Reilly D, McKane R, et al. Can rheumatologists agree on a diagnosis of inflammatory arthritis in an early synovitis clinic? Ann Rheum Dis 2001;60:638-3.

\title{
Anti-annexin $\mathrm{V}$ antibodies in patients with cerebrovascular disease
}

\author{
N Gašperšič, U Rot, S Čučnik, T Kveder, B Božič, B Rozman
}

A nnexin V (ANXV) is a protein with a high affinity for negatively charged phospholipids and shows in vitro a potent anticoagulant activity. It has been suggested that it has a significant role in the prevention of arteriovenous thromboses or fetal loss, or both. ${ }^{1}$ Increased levels of antibodies against ANXV (aANXV) have been reported in patients with different systemic autoimmune disorders ${ }^{2-4}$ as well as in women with recurrent fetal loss and pre-eclampsia. ${ }^{5}$ The presence of aANXV in patients with thromboembolic cerebrovascular disease (CVD), however, has not yet been described. We report on two patients with CVD who had evidently raised levels of IgG aANXV, whereas all the other tested antiphospholipid antibodies (aPL) were negative.

We examined 37 young patients with no evident systemic autoimmune disease ( 23 women, 14 men; mean age at CVD 32 years (range 18-40)) 11 months to six years after CVD: seven with transient ischaemic attack (TIA), 25 with ischaemic cerebrovascular insult, and five with venous sinus thrombosis. Diagnoses based on the history and clinical manifestations were objectively verified by computed tomography (CT), magnetic resonance imaging (MRI), and/or angiography at the time of the onset of symptoms. After prospective clinical re-examination, two blood samples were obtained from each patient eight weeks apart.

Serum samples were analysed by enzyme linked immunosorbent assay (ELISA) for the presence of $\mathrm{aANXV}^{5}$ anticardiolipin, ${ }^{6}$ anti- $\beta_{2}$-glycoprotein, ${ }^{7}$ and anti-prothrombin antibodies. ${ }^{8}$ Antinuclear antibodies (ANA) were determined by indirect immunofluorescence.

\section{CASE REPORTS \\ Patient 1}

A 36 year old woman with a history of fetal loss in 1982 became pregnant for the second time in 1998. At the 36th gestation week a caesarean section was performed owing to placental abruption. A few days after the delivery, she became somnolent with mild right sided hemiparesis. CT and an MRI scan confirmed superior sagittal sinus thrombosis and therefore treatment with warfarin was started. Three years later, her condition was stable with mild occasional headaches and mild right sided pyramidal symptomatology. Laboratory examinations showed positive ANA (up to $1 / 320$ ) and persistently raised levels of IgG aANXV, while all the other tested aPL were negative. No clinical manifestations of a systemic autoimmune disease could be found. Except for a short period of smoking, no other thrombotic risk factors were identified.

\section{Patient 2}

A 24 year old woman had a TIA in 1996, two months after starting hormonal contraceptives. She experienced paraesthesia over both arms and legs and gait ataxia was found. MRI, echocardiography, and sonography of the neck vessels were normal, suggesting TIA in the vertebrobasilar region. In 2000 she became pregnant for the first time. Generalised oedema and hypertension appeared in the fifth and eighth month, respectively. A healthy child was born one month pre-term. In 2001 she was in good health except for rather frequent headaches. Clinical and special neurological examinations were completely normal. Among the tested aPL only IgG aANXV were found to be positive. Contraceptives were the only risk factor for CVD.

\section{DISCUSSION}

ANXV is one of the possible cofactors for aPL. Rand et al reported that aPL can disrupt the protective shield of ANXV on procoagulant surfaces, ${ }^{9}$ leaving sufficient space for the formation of coagulation complexes. aANXV were shown to induce the apoptosis of endothelial cells, creating a procoagulant environment ${ }^{10}$ with increased risk for thrombosis.

Two of 37 young patients after CVD had significantly raised IgG aANXV only. Besides some CVD risk factors (smoking, delivery and bleeding, oral contraceptives) both patients had pregnancy complications, which might be associated with aANXV. $^{5}$ Our results did not show a statistically significant association between aANXV and CVD. Nevertheless it is possible that aANXV represented an additional risk factor, and together with other factors might have led to thrombosis. A study of larger groups of patients will enable firm conclusions to be drawn about the clinical significance of aANXV in CVD. 


\section{Authors' affiliations}

N Gašperšič, S Čučnik, T Kveder, B Božič, B Rozman, Department of Rheumatology, University Medical Centre, Ljubljana, Slovenia U Rot, Department of Neurology, University Medical Centre, Ljubliana, Slovenia

Correspondence to: Professor B Rozman, University Medical Centre, Department of Rheumatology, Vodnikova 62, SI-1000 Ljubljana,

Slovenia; kc.li.rozman@siol.net

Accepted 20 June 2002

\section{REFERENCES}

1 Matsuda J, Saitoh N, Gonchi K, Gotoh M, Tsukamoto M. Anti-annexin V antibody in systemic lupus erythematosus patients with lupus anticoagulant and/or anticardiolipin antibody. Am J Hematol 1994;47:56-8.

2 Rodriguez-Garcia MI, Fernandez JA, Rodriguez A, Fernandez MP Gutierrez C, Torre-Alonso JC. Annexin V autoantibodies in rheumatoid arthritis. Ann Rheum Dis 1996:55:895-900.

3 Sugiura K, Muro Y. Anti-annexin V antibodies and digital ischemia in patients with scleroderma. J Rheumatol 1999;26:2168-72.
4 Ogawa H, Zhao D, Dlott JS, Cameron GS, Yamazaki M, Hata T, et al. Elevated anti-annexin $\mathrm{V}$ antibody levels in antiphospholipid syndrome and their involvement in antiphospholipid antibody specificities. Am J Clin Pathol 2000;1 14:619-28.

5 Matsubayashi $\mathbf{H}$, Arai T, Izumi S, Sugi T, Mclntyre JA, Makino T. Anti-annexin $\mathrm{V}$ antibodies in patients with early pregnancy loss or implantations failures. Fertil Steril 2001;76:694-9.

6 Božič B, Stegnar M, Kveder T, Morosini-Berus E, Kos-Golja M, Peternel P, et al. Influence of degraded phosphatidylserine on binding of antiphospholipid antibodies. Int Arch Allerg Immunol 1997;1 12:19-26.

7 Avčin T, Ambrožič A, Kuhar M, Kveder T, Rozman B. Anticardiolipin and anti- $\beta_{2}$ glycoprotein I antibodies in sera of 61 apparently healthy children at regular preventive visits. Rheumatology (Oxford) 2001;40:565-73

8 Atsumi T, leko M, Bertolaccini LM, Ichikawa K, Tsutsumi A, Matsuura E, et al. Association of autoantibodies against the

phosphatidylserine-prothrombin complex with manifestations of the antiphospholipid syndrome and with the presence of lupus anticoagulant. Arthritis Rheum 2000;43:1982-93.

9 Rand JH, Wu XX, Andree HAM, Ross JBA, Rusinova E, Gascon-Lema $M G$, et al. Antiphospholipid antibodies accelerate plasma coagulation by inhibiting annexin-V binding to phospholipids: a "lupus procoagulant" phenomenon. Blood 1998:92:1652-60.

10 Nakamura N, Ban T, Yamaji K, Yoneda Y, Wada Y. Localisation of the apoptosis-inducing activity of lupus anticoagulant in an annexin V-binding antibody subset. J Clin Invest 1998;101:1951-9.

\title{
Intra-alveolar haemorrhage in temporal arteritis
}

\author{
D Le Thi Huong, M R Andreu, P Duhaut, P Godeau, J C Piette
}

Ann Rheum Dis 2003;62:189-190

$\mathrm{T}$ emporal arteritis (TA) is the most common systemic vasculitis. We report herein a case of TA complicated with intra-alveolar haemorrhage. To our knowledge, this manifestation has not previously been reported.

\section{CASE REPORT}

A woman born in 1926 presented in 1999 with persistent dry cough and raised erythrocyte sedimentation rate at $60 \mathrm{~mm}$ at the first hour. C reactive protein was $14 \mathrm{mg} / \mathrm{l}$. She had a history of pulmonary tuberculosis treated in 1951 with streptomycin and $p$-aminosalicylic acid. She complained of headache without fever, jaw claudication, scalp tenderness, and visual or musculoskeletal manifestations. She denied any other upper airways symptoms. Physical examination was normal. Arterial pressure was $140 / 70 \mathrm{~mm} \mathrm{Hg}$. Leucocyte count was $6.8 \times 10^{9} / 1$ with $4.2 \times 10^{9} / 1$ polynuclear neutrophils and $0.2 \times 10^{9} / 1$ eosinophils, haemoglobin $130 \mathrm{~g} / \mathrm{l}$, and platelets $310 \times 10^{9} / 1$. A dipstick urinary test showed no proteinuria and no haematuria. Chest radiography disclosed calcified nodular density in the upper right lobe, which was confirmed by computed tomography. An electrocardiogram and echocardiogram were normal. Fibre optic bronchoscopy was normal. Bronchoalveolar lavage fluid examination showed $120 \times 10^{9}$ cells/l, comprising macrophages 56\% with siderophages $30 \%$, lymphocytes $39 \%$, polynuclear neutrophils $1 \%$, and polynuclear eosinophils $4 \%$. Bronchoalveolar lavage was sterile on cultures for bacterial infection, Mycobacterium tuberculosis, cytomegalovirus, parasites, and fungi. A search for antinuclear antibodies and cryoglobulin was negative. Histological study of the temporal artery disclosed a granulomatous inflammation of the vessel wall containing mononuclear cells and histiocytes without giant cells, leading to fragmentation of the elastic lamina.

Prednisone $30 \mathrm{mg}$ daily was started. The headache and cough disappeared rapidly. At the two year follow up, the patient is asymptomatic with $7 \mathrm{mg}$ daily prednisone. $\mathrm{C}$ reactive protein is negative.

\section{DISCUSSION}

This patient had four of five American College of Rheumatology criteria for the classification of TA, which have a sensitivity of $93.5 \%$ and a specificity of $91.2 \% .^{1}$ Chronic dry cough without any chest radiograph anomaly is a classical symptom of TA. Machado in Minnesota reported respiratory symptoms in up to $25 \%$ of cases of TA. ${ }^{2}$ Cough may be the sole manifestation of the disease for a long time-up to one year. ${ }^{3}$ A three year course of cough associated with upper limb arteritis was also reported as an initial symptom of TA. ${ }^{4}$ The origin of the cough is not clear. In rare cases, cough might have been attributed to pleural effusion, interstitial pneumonitis, pulmonary vasculitis, or hyperreactive airways.

Blockmans et al found T4 lymphocytic alveolitis in three patients with histologically proved TA. ${ }^{6}$ Only one patient complained of dry cough and dyspnoea. Chest radiographs and lung function tests were always normal. Cell count was normal on bronchoalveolar lavage fluid examination, but the number of lymphocytes was increased, as in our case, with a percentage varying between 16 and $61 \%$. Discovery of nodular parenchymal densities raises the question of a borderline systemic vasculitis with Wegener granulomatosis. ${ }^{4}$

In our case, there was no obvious cause for intra-alveolar haemorrhage besides TA. Congestive cardiac failure and exogenous agents were excluded. Bacteriological, viral, fungal, and parasitic studies of bronchoalveolar lavage fluid were negative. There was no manifestation suggesting another systemic disease such as microscopic polyangiitis, Wegener's granulomatosis or vasculitis secondary to systemic lupus erythematosus. The favourable outcome with medium dose prednisone in the absence of any other immunosuppressive agent also suggests TA. Cytomegalovirus infection was ruled out, but not other viral infections. Several viruses such as cytomegalovirus, ${ }^{7}$ coxsackievirus, ${ }^{8}$ adenovirus, ${ }^{9}$ enterovirus, ${ }^{10}$ mumps, ${ }^{11}$ and hepatitis $\mathrm{C}$ virus ${ }^{12}$ can cause pulmonary haemorrhage. Some authors have suggested that TA has a viral cause, and various agents were incriminated. Varicella zoster $^{13}$ and parvovirus B19 DNA $^{14}$ were found in temporal biopsy specimens of 
patients with histologically proved TA. IgM directed against human para-influenza type 1 virus were associated with TA onset. $^{15}$

In conclusion, intra-alveolar haemorrhage may be one of the various causes of cough in TA. Further studies are necessary to ascertain whether it is the expression of a primary vasculitis or the consequence of an as yet unknown viral infection.

\section{Authors' affiliations}

D Le Thi Huong, M R Andreu, P Duhaut, P Godeau, J C Piette,

Department of Internal Medicine, Groupe Hospitalier Pitié-Salpêtrière, 83 bd de l'Hôpital, 75013 Paris, France

Correspondence to: Dr D Le Thi Huong; du.boutin@wanadoo.fr

Accepted 20 June 2002

\section{REFERENCES}

1 Hunder GG, Bloch DA, Michel BA, Stevens MB, Arend WP, Calabrese $\mathrm{LH}$, et al. The American College of Rheumatology 1990 criteria for the classification of giant cell arteritis. Arthritis Rheum 1990;33:1122-8.

2 Machado EBV, Michet CJ, Ballard DJ, Hunder GG, Beard CM, Chu CP et al. Trends in incidence and clinical presentation of temporal arteritis in Olmested County, Minnesota, 1950-1985. Arthritis Rheum 1988;31:745-9

3 Joomaye Z, Sotto A, Jourdan J. Toux isolée prolongée due à la maladie de Horton. Rev Mal Respir 1997; 14:59-60.

4 Rischmueller M, Davies RP, Smith MD. Three year follow-up of a case of giant cell arteritis presenting with a chronic cough and upper limb ischaemic symptoms. Br J Rheumatol 1996;35:800-2.
5 Le Thi Huong D, de Gennes C, Papo T, Wechsler B, Bletry O, Piette JC, et al. Manifestations pleuropulmonaires des vascularites systémiques. Rev Med Interne 1996;17:640-52.

6 Blockmans D, Knockaert D, Bobbaers H. Giant cell arteritis can be associated with T4-lymphocytic alveolitis. Clin Rheumatol 1999; 18:330-3.

7 Herry I, Cadranel J, Antoine M, Meharzi J, Michelson S, Parrot A, et al. Cytomegalovirus-induced alveolar hemorrhage in patients with AIDS: a new clinical entity? Clin Infect Dis 1996;22:616-20

8 KaplanMH, Klein SW, McPhee J, Harper RG. Group B coxsackievirus infections in infants younger than three months of age: a serious chilhood illness. Rev Infect Dis 1983:5:1019-32.

9 Abbondanzo SL, English CK, Kagan E, McPherson RA. Fatal adenovirus pneumonia in a newborn identified by electron microscopy and in situ hybridization. Arch Pathol Lab Med 1989;1 13:1349-53.

10 Ho M, Chen ER, Hsu KH, Twu SJ, Chen KT, Tsai SF, et al. An epidemic of enterovirus 71 infection in Taiwan. Taiwan Enterovirus Epidemic Working Group. N Engl J Med 1999;341:929-35.

11 Takahashi Y, Teranishi A, Yamada Y, Yoshida Y, Hashimoto K, Sakamoto $Y$, et al. A case of congenital mumps infection complicated with persistent pulmonary hypertension. Am J Perinatol 1998;15:409-12.

12 Gomez-Tello V Onoro-Canaveral JJ, de la Casa Monje RM, Gomez-Casero RB, Moreno Hurtrez JL, Garcia-Montes M, et al. Diffuse recidivant alveolar hemorrhage in a patient with hepatitis $C$ virus-related mixed cryoglobulinemia. Intensive Care Med 1999;25:319-22.

13 Mitchell BM, Font RL. Detection of varicella zoster virus DNA in some patients with giant cell arteritis. Invest Ophthalmol Vis Sci 2001:42:2572-7.

14 Gabriel SE, Espy M, Erdman DD, Bjornsson J, Smith TF, Hunder GG. The role of parvovirus B19 in the pathogenesis of giant cell arteritis: a preliminary evaluation. Arthritis Rheum 1999;42:1255-8.

15 Duhaut P, Bosshard S, Calvet A, Pinede L, Demolombe-Rague S, Dumontet $C$, et al. Giant cell arteritis, polymyalgia rheumatica, and viral hypotheses: a multicenter, prospective case-control study. Groupe de Recherches sur l'Artérite à Cellules Géantes. J Rheumatol 1999;26:361-9.

\title{
Circulating soluble CD4O ligand in patients with eosinophilic fasciitis
}

\author{
M Jinnin, H Ihn, N Yazawa, Y Asano, K Yamane, K Tamaki
}

Ann Rheum Dis 2003;62:190-191

R Recently, some reports showed the increased expression of CD40 ligand in autoimmune diseases. CD40 ligand can be expressed in a soluble form. ${ }^{12}$ Soluble CD40 ligand (sCD40L) is present in supernatants of in vitro activated T cells in $15 \mathrm{kDa}$ and $18 \mathrm{kDa}$ forms, and these forms are the products of enzymatic cleavage at a metalloproteinase sensitive site in the membrane proximal region of the extracellular domain of the molecule. ${ }^{1}$ Their abnormalities have been demonstrated in various kinds of diseases such as chronic lymphocytic leukaemia ${ }^{2}$ or systemic lupus erythematosus. ${ }^{1}$ But, there has been no report demonstrating the serum levels of sCD40L in patients with eosinophilic fasciitis (EF). In this study we determined the serum levels of sCD40L in patients with EF, and investigated their clinical significance in this disease, in order to evaluate whether sCD40L might be a useful marker for this disease.

\section{METHODS AND RESULTS}

Eleven patients (disease duration 1-8 months) with a classic clinical picture of EF, who had received no treatment, were included in this study. All the patients had a recent history of increased skin induration. Skin biopsies including deep subcutaneous tissue and fascia showed markedly indurated and thickened fascia in all cases. Additionally, the thickened fascia contained accumulation of collagen and intense inflammatory cell infiltrates comprising lymphocytes, macrophages, and eosinophils. Clinical manifestations and labora- tory findings of each patient were obtained from the medical records. All the laboratory findings were obtained at the time of serum sampling. We also collected control serum samples from 20 healthy volunteers matched for age and sex. Levels of sCD40L were measured with a specific enzyme linked immunosorbent assay (ELISA) kit (Bender MedSystems, Vienna, Austria), according to the manufacturer's instructions. Values greater than the mean plus 2SD for normal control subjects were regarded as raised. Additionally, serum IgG was evaluated by a turbidimetric immunoassay as described previously. ${ }^{3}$ Statistical analysis was carried out with Student's $t$ test for the comparison of means, and Fisher's exact probability test for the analysis of frequency. Values of $p<0.05$ were considered significant.

Figure 1 shows the serum sCD40L levels in patients with EF and in the healthy control subjects. The serum sCD40L levels in patients with EF were significantly higher than those in the healthy controls (mean (SD) $0.29 \quad(0.16) \quad \mathrm{ng} / \mathrm{ml}$ $v 0.13(0.08) \mathrm{ng} / \mathrm{ml}, \mathrm{p}<0.01)$. When the cut off value was set at $0.29 \mathrm{ng} / \mathrm{ml}$ (mean $+2 \mathrm{SD}$ for the controls), raised serum sCD40L levels were seen in 5/11 (45\%) patients with EF.

Serum sCD40L levels correlated significantly with serum IgG levels $(r=0.75, \mathrm{p}<0.05)$. On the other hand, serum sCD40L levels were not significantly correlated with serum gammaglobulin, peripheral cell count of eosinophils, erythrocyte sedimentation rate, or serum levels of aldolase. Additionally, three of the five patients with raised serum 


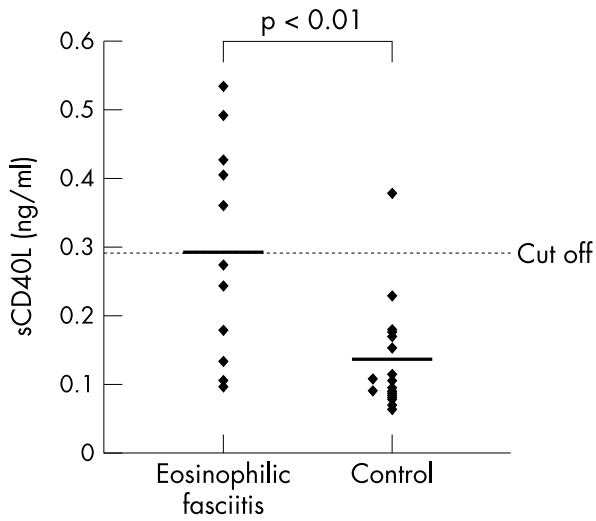

Figure 1 Serum soluble CD40 ligand (sCD4OL) levels determined with specific ELISAs in serum samples from patients with EF and healthy control subjects. Bars show means. The horizontal dotted line represents $2 \mathrm{SD}$ above the mean value of healthy controls. p Values were determined by Student's $t$ test.

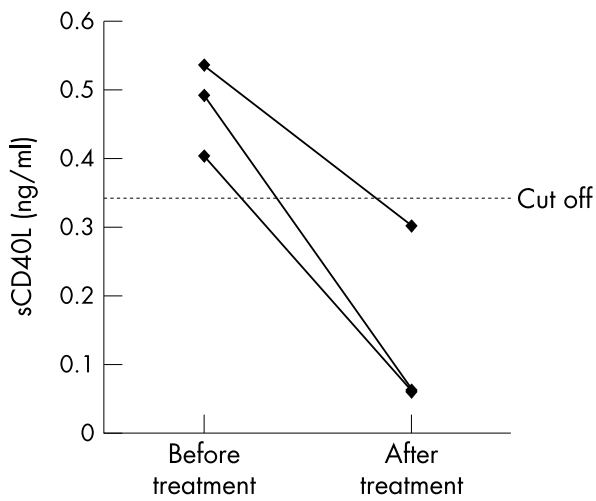

Figure 2 Longitudinal study of serum soluble CD40 ligand (sCD40L) levels in patients with EF.

sCD40L levels were examined longitudinally before and after corticosteroid treatment for two months to three years. Their clinical manifestations and laboratory abnormalities improved with treatment. Serum sCD40L levels became normal in all three patients (fig 2).

\section{DISCUSSION}

As described above, expression of sCD40L in patients with several connective tissue diseases has already been evaluated and shown to be increased. Berner et al reported that increased expression of CD40 ligand on CD4 $+\mathrm{T}$ cells in rheumatoid arthritis indicated prolonged and increased activation of $\mathrm{CD} 4+\mathrm{T}$ lymphocytes and was associated with active disease and, possibly, an unfavourable prognosis. ${ }^{4}$ Valentini et al found that expression of CD40 ligand in activated CD4+ T lymphocytes was increased in patients with systemic sclerosis. ${ }^{5}$ On the other hand, Vakkalanka et al reported that the mean concentration of serum sCD40L was statistically significantly higher in patients with systemic lupus erythematosus (SLE) than in disease controls or healthy subjects, and segregation of patients with SLE by severe, moderate, or mild extent of disease showed a relationship between disease severity and sCD40L concentration. ${ }^{1}$ These findings suggest that CD40 ligand or SCD40L are associated with clinical features of these diseases. In our study, serum levels of sCD40L in patients with EF were significantly higher than those in healthy controls. SCD40L is present in supernatants of in vitro activated T cells. ${ }^{1}$ In patients with EF, activated T cells were thought to be increased because of the presence of raised interleukin 5 and interleukin $10{ }^{6}$ Thus, our results may reflect such a condition. Additionally, serum levels of sCD40L correlated significantly with serum IgG levels in patients with EF, and serum sCD40L levels normalised after treatment in patients with raised sCD40L levels. As well as peripheral cell counts of eosinophils, erythrocyte sedimentation rate or serum levels of aldolase, hypergammaglobulinaemia is reported to be one of the markers of disease activity, ${ }^{78}$ which occurs in $75 \%$ of patients and is usually due to a polyclonal increase in IgG. ${ }^{9}$ Thus, our results suggest that $\mathrm{SCD} 40 \mathrm{~L}$ is also good marker of EF, reflecting the effects of treatment. However, only 5/11 patients showed raised levels of sCD40L. Thus, the usefulness of SCD40L as a marker of disease activity was not completely substantiated in this study. Additionally, serum SCD40L levels did not correlate with gammaglobulin despite significant correlation with $\operatorname{IgG}$, possibly owing to the small number of patients studied. Moreover, we performed the longitudinal study in only three patients with raised sCD40L levels because other serum samples were not available, so the longitudinal data may be incomplete. Additionally, there is a possibility that corticosteroid treatment, independently of disease, can reduce $\mathrm{sCD} 40 \mathrm{~L}$ levels. Further studies are needed to clarify the significance of the role of SCD40L in this disease.

\section{Author's affiliations}

M Jinnin, H Ihn, N Yazawa, Y Asano, K Yamane, K Tamaki, Department of Dermatology, Faculty of Medicine, University of Tokyo, 7-3-1 Hongo, Bunkyo-Ku, Tokyo 11 3-8655, Japan

Correspondence to: Dr H Ihn; IN-DER@h.u-tokyo.ac.jp

Accepted 7 June 2002

\section{REFERENCES}

1 Vakkalanka RK, Woo C, Kirou KA, Koshy M, Berger D, Crow MK. Elevated levels and functional capacity of soluble CD40 ligand in systemic lupus erythematosus sera. Arthritis Rheum 1999;42:871-81.

2 Hollenbaugh D, Grosmire I, Kullas C, Chalupny NJ, Braesch-Andersen $\mathrm{S}$, Noelle RJ, et al. The human T cell antigen gp39, a member of the TNF gene family, is a ligand for the CD40 receptor: expression of a soluble form of gp39 with B cell costimulatory activity. EMBO J 1992:11:4314-21.

3 Bergstrom $M$, Lefvert AK. An automated turbidimetric immunoassay for plasma proteins. Scand J Clin Lab Invest 1980;40:637-40.

4 Berner B, Wolf G, Hummel KM, Muller GA, Reuss-Borst MA. Increased expression of CD40 ligand (CD154) on CD4+ T cells as a marker of disease activity in rheumatoid arthritis. Ann Rheum Dis 2000;59:190-5.

5 Valentini G, Romano MF, Naclerio C, Bisogni R, Lamberti A, Turco MC et al. Increased expression of CD40 ligand in activated CD4+ T lymphocytes of systemic sclerosis patients. J Autoimmun 2000;15:61-6.

6 Viallard JF, Taupin JL, Ranchin V, Leng B, Pellegrin JL, Moreau JF. Analysis of leukemia inhibitory factor, type 1 and type 2 cytokine production in patients with eosinophilic fasciitis. J Rheumatol 2001;28:75-80

7 Falanga V, Medsger TA. Frequency, levels, and significance of blood eosinophilia in systemic sclerosis, localized scleroderma, and eosinophilic fasciitis. J Am Acad Dermatol 1987; 17:648-56.

8 Fujimoto $\mathbf{M}$, Sato S, Ihn H, Kikuchi K, Yamada N, Takehara K. Serum aldolase level is a useful indicator of disease activity in eosinophilic fasciitis. J Rheumatol 1995:22:563-5.

9 Doyle JA, Glinsberg WW. Eosinophilic fasciitis. Med Clin North Am 1989;73:1 157-66 